\title{
Os projetos de trabalho: Uma experiência integradora na formação inicial de professores
}

\author{
Eulália Neto ${ }^{i}$ \\ IFRN, Brasil
}

\begin{abstract}
Resumo
O presente artigo tem como objetivo problematizar o papel da investigação nos cursos de formação inicial de professores a partir do relato de uma experiência com projetos integradores (PI). Fundamenta o seu desenvolvimento em três conceitos organizadores: formação inicial de professores, currículo integrado e interdisciplinaridade. Discute a importância de um currículo de formação que possibilite a relação teoria e prática, o diálogo entre as disciplinas, a reflexão e a crítica. Destaca a importância da disponibilidade dos professores de diferentes áreas disciplinares no compartilhamento de suas experiências, seus saberes, suas certezas e incertezas. Tem como contexto de análise o relatório elaborado pelo grupoclasse de uma turma do terceiro período da licenciatura em Espanhol. Baseiase nos princípios da pesquisa qualitativa. Destaca os indicadores que apontam a integração das disciplinas a partir do PI e a importância deste para a formação do professor-pesquisador e para a integração do grupo-classe.
\end{abstract}

Palavras-chave

Formação inicial de professores; Currículo integrado; Projetos integradores

\section{Introdução}

$\mathrm{O}$ artigo que se apresenta tem como objetivo problematizar o papel da investigação nos cursos de formação inicial de professores a partir do relato 
de uma experiência com projetos de trabalho. Para tanto, fundamenta o seu desenvolvimento em três conceitos organizadores: formação inicial de professores, currículo integrado e interdisciplinaridade. A nossa preocupação com a interdisciplinaridade e com o currículo integrado ${ }^{1}$ se deu pelo fato de atuarmos em uma instituição que oferece, dentre outros, cursos de formação de professores e curso de Ensino Médio Integrado ao Técnico². Este último se propõe a contribuir com uma formação humana que integre, com o mesmo grau de importância, a ciência, o trabalho, a cultura e a tecnologia:

Trata-se de um modelo de oferta de educação profissional técnica de nível médio que visa promover uma formação orientada para a emancipação, no sentido de formar um trabalhador consciente de seu potencial transformador de dada realidade social, possibilitando-lhe o domínio das esferas produtivoculturais da humanidade (Instituto Federal de Educação, Ciência e Tecnologia do Rio Grande do Norte [IFRN], s/d).

Neste sentido, podemos afirmar que a prática educativa se desenrola em um contexto singular, com uma cultura própria e com o envolvimento de pessoas de estratos sociais específicos. Daí por que o ensino deve ser orientado numa perspectiva multidimensional, na qual se entrecruzem as dimensões humanas, técnicas e político-sociais, tornando-se, assim, elemento importante na consolidação da função social da instituição escolar.

Diante do exposto, levantamos a hipótese de que os cursos de formação inicial de professores devem proporcionar um ensino voltado para a formação humana e integral do aluno, com 0 intuito de que ele, futuro professor, a considere na prática docente. Para tanto, ressaltamos a importância da investigação e dos projetos de trabalho nos referidos cursos.

Com vistas a discutirmos a importância dos projetos de trabalho para a consecução de currículos integrados, organizamos este artigo apresentando: inicialmente, os três conceitos organizadores de forma entrecruzada; num segundo momento, o conceito de projeto integrador (PI) por nós adotado e os seus princípios organizativos; e, num terceiro momento, o relato de uma experiência com PI que tivemos a oportunidade de vivenciar ${ }^{3}$, cuja orientação se baseia nos pressupostos da interdisciplinaridade.

O material utilizado como subsídio para o levantamento e para a análise da problemática em questão se constitui do Relatório de Atividades do Projeto Integrador realizado pelos alunos de uma turma de terceiro semestre 
do Curso de Licenciatura em Espanhol. Destacamos, em especial, os indicadores que apontam a integração das disciplinas a partir do PI e a importância deste para a formação do professor-pesquisador e para a integração do grupo-classe.

Por fim, sintetizamos as considerações finais deste estudo procurando responder à questão: Em que medida experiências interdisciplinares baseadas na construção de PI podem contribuir para a integração curricular e o desenvolvimento de atitudes de pesquisa e da colaboração?

\section{Currículo integrado e interdisciplinaridade na formação do professor}

Investigar a importância de um currículo interdisciplinar ${ }^{4}$ para a formação do futuro docente torna-se significante para nós, na medida em que percebemos que a construção de uma identidade profissional assenta, dentre outros, nas experiências vivenciadas durante os cursos de formação inicial, por estes serem um espaço de construção do conhecimento, pois, segundo Silva (2011), "A construção do conhecimento profissional docente é pautada por factores diversos, que tornam a sua sistematização necessariamente enquadrada num contexto organizacional e curricular (...)" (p. 607).

A razão por que optamos por esse recorte epistemológico deveu-se ao fato de que, como professora de Didática, colocamo-nos diariamente diante de várias interrogações e desafios em relação à prática docente do professorformador e em relação à formação de conceitos necessários a uma prática pedagógica integradora. Como suporte para a nossa reflexão, consultamos o projeto político e pedagógico (PPP) do Instituto Federal de Educação, Ciência e Tecnologia do Rio Grande do Norte (IFRN), que considera o currículo como:

(...) conjunto integrado e articulado de atividades intencionadas, pedagogicamente concebidas a partir da visão crítica de ser humano, de mundo, de sociedade, de trabalho, de cultura e de educação, organizadas para promover a construção, a reconstrução, a socialização e a difusão do conhecimento (IFRN, 2010).

Segundo o documento acima referido, o currículo integrado propõe, a partir de um aporte histórico-crítico, "a formação integral dos educandos, objetivando, também, torná-los cidadãos aptos a contribuir com o desenvolvimento socioeconômico local, regional, nacional e global (...)" 
(IFRN, 2010) sob os eixos do trabalho, da ciência e da cultura integrados à tecnologia.

Ao refletir sobre o currículo integrado, Ramos (2012) nos indica que:

No 'currículo integrado', conhecimentos de formação geral e específicos para o exercício profissional também se integram. Um conceito específico não é abordado de forma técnica e instrumental, mas visando a compreendê-lo como construção histórico-cultural no processo de desenvolvimento da ciência com finalidades produtivas. Em razão disto, no 'currículo integrado' nenhum conhecimento é só geral, posto que estrutura objetivos de produção, nem somente específico, pois nenhum conceito apropriado produtivamente pode ser formulado ou compreendido desarticuladamente das ciências e das linguagens.

Percebemos, pois, que o currículo integrado, para se constituir como tal, terá necessariamente de ser organizado de forma a possibilitar a relação teoria e prática, o diálogo entre as disciplinas, a reflexão e a crítica sobre a realidade social na qual a comunidade escolar está inserida. Deste modo, podemos afirmar que o currículo integrado é essencialmente interdisciplinar, pois a interdisciplinaridade "(...) torna possível a complementaridade dos métodos, dos conceitos, das estruturas e dos axiomas sobre os quais se fundam as diversas práticas científicas" (Japiassú, 1996, p. 145).

A partir da análise do PPP do IFRN, consideramos que os cursos de formação de professores a serem oferecidos por esse Instituto necessitam de uma organização didático-pedagógica que possibilite ao futuro docente trabalhar com práticas interdisciplinares, já que este se encontra inserido em uma instituição que prima, em seus documentos normativos, por um trabalho acadêmico integrador. Convém ressaltarmos, no entanto, que diversos estudos (Fazenda, 1995; Severino, 2004; Hernàndez, 1998) demonstram que a ação docente revestida de um caráter interdisciplinar requer de professores e alunos a compreensão de que não há uma única e absoluta teoria científica e que a provisoriedade da verdade e da ciência nos impõe a necessidade de pesquisa permanente. Pensar a prática docente sob esse prisma implica, assim, considerar o caráter inacabado, dinâmico e complexo da formação docente, o que requer do professor formador e do aluno formando uma permanente busca por conhecimentos significativos e interdependentes.

Dentro de uma perspectiva humanista e crítica de educação, Freire (1996) nos assevera que ser pesquisador não é uma qualidade que se "(...) acrescenta à de ensinar. Faz parte da prática docente a indagação, a busca, 
a pesquisa. $O$ de que se precisa é que, em sua formação permanente, o professor se perceba e se assuma, porque professor, como pesquisador" ( $p$. 32). Essa busca deve caracterizar-se como uma constante, na medida em que a prática docente envolve uma multiplicidade de tarefas interrelacionadas. Por isto, compreender o contexto no qual os futuros professores estão inseridos ou nele irão ser inseridos, a partir de um trabalho integrado e interdisciplinar, torna-se fundamental para sua formação.

\section{O papel dos projetos integradores na formação de professores}

Acreditamos, pois, que o trabalho com projetos, enquanto procedimento teórico e metodológico que liga a interdisciplinaridade com a investigação e a teoria com a prática, poderá realçar o entendimento dos contextos escolares, ao colocar o futuro docente em contato direto com a realidade do cotidiano escolar e ao minimizar a compartimentação das disciplinas, além de propor o ressignificar das práticas de formação inicial de professores, a interação alunos/docente/comunidade e o sentido do planejamento, do currículo e da pesquisa como elementos fundamentais para a construção do conhecimento nas instituições formadoras. Neste sentido, Canário (2002) chama a atenção para

(...) a necessidade de que os contactos dos futuros professores com as situações profissionais reais sejam os mais precoces possíveis e estejam presentes ao longo de todo o percurso de [formação] (...). Só assim será possível estabelecer um relacionamento entre o contexto escolar e o contexto do trabalho que favoreça um processo de dupla mobilização: mobilizar os saberes teóricos para o investimento na acção e formalizar (investindo no trabalho teórico) os saberes adquiridos por via experiencial (p. 47).

A prática pedagógica que se desenvolve a partir da pesquisa que mobiliza saberes teóricos e práticos desenvolve-se em contextos reais, carregados de intenções e de interpretações subjetivas. Deste modo, tal prática torna-se práxis porque, como atividade humana, pressupõe a idealização consciente por parte do sujeito que se propõe a interferir na realidade, transformando-a, o que nos leva a concluir que a unidade teoria e prática se caracteriza pela ação-reflexão-ação. Essa unidade possibilita ao professor perceber "a escola como um espaço político, limitado, mas de importância relativa na superação das contradições da sociedade" (Gadotti, 
2003, p. 171). Assim, na organização do trabalho docente, dá-se sempre um vínculo entre finalidade e ação, entre saber e fazer, entre concepção e realização, o que resulta numa ação recíproca entre professor, aluno, conhecimento e realidade acentuadamente consciente.

Segundo Alonso (2007),

(...) o perfil do professor actual é o de um profissional apetrechado com os instrumentos teóricos, técnicos e práticos que lhe permitem desempenhar uma prática reflexiva, capaz de dar resposta à diversidade de exigências com que é confrontada a escola de hoje e do futuro. A sua função central - estimular aprendizagens significativas nos alunos e o seu desenvolvimento integral enquanto indivíduos e cidadãos - é uma função complexa, que exige o desenvolvimento de conhecimentos, capacidades e atitudes a vários níveis, mas que exige, sobretudo, uma grande capacidade reflexiva, investigativa, criativa e participativa para se adaptar e intervir nos processos de mudança ( $p$. 115).

Para atender a esse perfil, os cursos de formação necessitam estruturar-se a partir de currículos que promovam a participação ativa e colaborativa dos envolvidos nos processos de ensino e aprendizagem. Tal perspectiva nos traz uma "concepção processual, dinâmica e aberta de currículo (...) concebendo-o antes como texto que, a partir de uma primeira elaboração base, se vai transformando, enriquecendo, reconstruindo e, por vezes, deteriorando e desvirtuando (...)" (Alonso, 2000, p. 61).

Neste sentido, os saberes que nutrem a reflexão sobre a profissão docente e que integram os currículos de formação devem ser construídos pelos formandos mediante o incentivo pela busca de novas fontes de informação e de conhecimento. Para tanto, é importante que as instituições formadoras, desde a concepção e definição do seu projeto de formação, procurem fontes e estratégias que possibilitem o confronto de ideias e a pluralidade de opiniões sobre os contextos estudados e promovam situações de aprendizagem nas quais o aluno - futuro professor - possa ganhar autonomia na busca pelo conhecimento e posicionar-se de forma teórica e prática diante dos fundamentos educacionais. Segundo defende Day (2001), professores e alunos "constroem activamente formas de saber, que funcionam como mapas dos seus mundos" (p. 308), uma vez que "o conhecimento do conteúdo e o conhecimento pedagógico não podem estar divorciados das necessidades pessoais e profissionais (...)" (Day, 2001, p. 17). 
Portanto, se considerarmos como importante uma educação para a autonomia, os currículos dos cursos de formação de professores devem ser flexíveis, de forma a respeitar a criatividade de professores e de alunos; deverão considerar como relevante o conhecimento produzido pelas mais diversas ciências e disponibilizar espaços de diálogo permanente entre os saberes elaborados pela Academia e os saberes elaborados fora dela.

Segundo Alonso e Silva (2005):

(...) a qualidade de um currículo de formação depende em grande medida da forma como, nas suas diferentes componentes, se criam (...) espaços de mediação entre a teoria e a prática utilizando para isso estratégias específicas para desenvolver a reflexão (p. 13).

Deste modo, as instituições formadoras, ao abrirem o currículo para os saberes construídos além de seus muros, através de trabalhos colaborativos, integrados e interdisciplinares, possibilitam ao futuro docente a construção de um saber profissional holístico e contextual, no qual a reflexão se faz presente.

De acordo com Roldão (2005), o saber docente consiste na

Mobilização complexa, organizada e coerente de todos esses saberes em torno de situações educativas concretas, no sentido da consecução do objectivo definidor da acção profissional - a aprendizagem do aluno. Desta mobilização reflectida e ajustada de saberes prévios (gestão de saber) resulta, por sua vez, a emergência de saber específico da profissão, que nasce do exercício da mesma e da dialéctica saberes/situações que o acto de ensinar envolve (produção do saber) (p. 18).

Neste sentido, o profissional professor deve ser aquele que, através de uma ação intencional, desenvolve uma orientação tutorizada que transforma o esforço do aluno na apreensão do saber. Para tanto, seu ofício "não pode ser associado ao mero domínio de conhecimento científico (...), nem reduzido aos conhecimentos científicos e metodológicos do campo das ciências da educação" (Roldão, 2005, p. 18). A prática docente envolve diversos saberes e estes devem ser construídos de forma entrecruzada, com vistas a uma ação conscientemente deliberada. 


\section{Os projetos integrados e a formação através da investigação}

Dentre os desafios apresentados às instituições formadoras, encontrase o de ensinar o futuro docente a observar seu percurso formativo e analisálo, levantar problemas, equacioná-los e contextualizá-los, buscando, deste modo, alternativas de solução. Assim, teremos uma formação comprometida com a construção profissional e cidadã, na qual o professor formador possibilita ao aluno formando desenvolver e ampliar continuamente seu universo socioafetivo e cognitivo através da reorganização de suas diretrizes pedagógicas. Tais desafios impõem a esse professor ousadia de criar, de inovar, de quebrar estigmas e rotinas estabelecidas, de buscar alternativas para redimensionar sua prática. Ademais, é imperioso considerar que o educador não nasce educador, nem mesmo marcado para exercer esse ofício: ele se forma permanentemente na prática e na reflexão que dela faz constantemente (Freire, 1996).

Os projetos integradores criam um ambiente de pesquisa colaborativo entre formadores e alunos. A investigação torna-se um elemento propulsor da construção do conhecimento. São criadas situações de aprendizagem que rompem com a falta de contextualização e possibilitam a efetivação de um trabalho significativo, além de promoverem a mobilização dos saberes e a conexão com as práticas sociais e políticas contemporâneas - atitudes essenciais ao professor na sociedade atual, pois, segundo nos alerta Alonso (2007), "a complexidade e paradoxismo que definem a condição social actual implicam determinadas pautas de relações sociais, económicas, políticas e culturais que afectam profundamente a escolarização e o trabalho dos professores" (p. 117).

Sendo assim, a atividade investigativa deve constituir-se como alicerce para o exercício de uma profissão docente, crítica e reflexiva. Partindo dessa premissa, afirmamos a importância dos projetos de trabalho nos currículos das licenciaturas, na perspectiva de contribuir para a formação do professor como profissional da educação (López, Gallego-Largo, Blanco \& Sanz, 1992) que identifica diferentes alternativas em sua ação e toma decisões conscientes relativas ao planejamento e ao desenvolvimento de sua própria prática. 


\section{Os projetos de trabalho: Relato de uma experiência integradora no curso de formação de professores}

Apresentamos a seguir a análise de uma experiência com projetos de trabalho realizada no Curso de Formação de Professores de Espanhol para o Ensino Fundamental e Médio, oferecido pelo IFRN. Nesta análise buscamos, como anunciado anteriormente, identificar a integração das disciplinas a partir do PI e a importância deste para a formação de professor- pesquisador e para a integração do grupo-classe.

\subsection{A construção do projeto integrador}

No projeto político-pedagógico do IFRN, os projetos integradores caracterizam-se como:

(...) uma diretriz teórico-metodológica assumida pela Instituição para o envolvimento de professores e alunos na busca da interdisciplinaridade, contextualização e flexibilidade com o objetivo de romper com a fragmentação do conhecimento, valorizando a pesquisa individual e coletiva e desenvolvendo atitudes necessárias à formação do professor pesquisador (IFRN, 2010).

A diretriz teórico-metodológica adotada pelo Instituto indica um trabalho no qual o conhecimento teórico e o conhecimento prático são indissociáveis na busca de um entendimento integral do fazer docente. Neste sentido, a mobilização de novas relações educativas é indispensável para a produção do conhecimento acadêmico e prático. A autoconsciência, a autonomia e a liberdade tornam-se elementos que coíbem o desrespeito ao saber do outro, a intolerância e a imposição de uma verdade única, na medida em que todos os saberes envolvidos na formação são considerados como importantes. Como exemplo dessa nova relação educativa, os projetos integradores têm como fio condutor a interação dialógica entre alunos e professores, alunos e alunos e entre os professores e seus pares.

Enquanto situação formativa, os PI implicam: a presença de sujeitos; a escolha de objetos de conhecimento - conteúdo; a definição de objetivos a que se destina a prática educativa; e a escolha de métodos, processos, técnicas e materiais didáticos. Todos esses elementos estão associados com "a opção política, com a utopia, com o sonho de que está impregnado o projeto educativo" (Freire, 2004, p. 88 - tradução nossa). 
Para que a proposta de integração se efetive, a elaboração da estrutura curricular dos cursos de formação de professores oferecidos pelo IFRN, e vigente no momento da realização do projeto, considerou que cada semestre letivo deveria ser composto por, pelo menos, três disciplinas que se aproximassem e possuíssem pontos em comum 5 , para que os vínculos existentes entre elas fossem evidenciados, como tecendo uma rede e tornando-as solidárias entre si (Roegiers \& De Ketele, 2004).

Como foi acima evidenciado, os PI caracterizam-se como uma diretriz teórico-metodológica dos cursos de formação de professores do IFRN. No entanto, neste trabalho vamo-nos cingir a uma experiência vivenciada em uma turma do $3^{\circ}$ período do Curso de Licenciatura em Espanhol.

O espaço curricular/organizativo em que se desenvolveu o PI envolvia as disciplinas de Didática, Semântica e Lexicologia, Língua Espanhola III e Morfossintaxes I, além de serem resgatados os conteúdos teóricos e metodológicos trabalhados nos dois semestres anteriores. Todo o percurso da pesquisa foi decidido em comum acordo com o grupo-classe, que era constituído por vinte e dois alunos e quatro professores formadores. Foram realizadas dezasseis reuniões, que se caracterizaram pelo acompanhamento de estudos, leitura de documentos, socialização, discussão e reflexão do processo de pesquisa inerente aos $\mathrm{PI}$. Todos os encontros foram registrados em atas lavradas a cada dia por um dos alunos formandos. Buscamos, assim, a valorização do trabalho colaborativo como o contexto primordial de formação (Alonso, 2007).

Inicialmente, o grupo-classe foi dividido em pequenos grupos para o levantamento de sugestões de temas e de objetivos de pesquisa. O tema a ser trabalhado deveria se caracterizar como transversal para as disciplinas oferecidas no semestre letivo em curso e participantes do projeto. Cada pequeno grupo apresentou suas sugestões e o tema escolhido foi: "O ensino do Espanhol em Natal, uma cidade que no habla". Os objetivos definidos foram: conhecer a realidade dos processos de ensino e aprendizagem do Espanhol nas escolas públicas de Ensino Médio de Natal; analisar a didática utilizada pelos professores de Espanhol no Ensino Médio; identificar as questões vivenciadas pelos estudantes do Espanhol como Língua Estrangeira (E/LE) no processo de aprendizagem. 
O trabalho baseou-se nos princípios da pesquisa qualitativa com recurso complementar à pesquisa quantitativa. Para a escolha das escolas que compuseram o campo de investigação foi feita uma visita à Secretaria de Estado de Educação e Cultura do Estado do Rio Grande do Norte, a fim de obter a lista das escolas que oferecem o Ensino de Língua Espanhola no Ensino Médio, já que esse componente curricular ainda não se fazia presente em todas as escolas do Estado. Foram selecionadas cinco escolas. Como instrumento de coleta de dados, foi utilizado o questionário, que se destinou a estudantes e professores da Língua Espanhola. A amostra da pesquisa foi constituída por seis professores que lecionavam essa Língua nas instituições que constituíram o campo de investigação e por $10 \%$ dos estudantes que se encontravam matriculados e frequentando regularmente as aulas de língua espanhola, nas respectivas escolas. Tais estudantes foram selecionados aleatoriamente através de sorteio.

Posteriormente, o grupo-classe procedeu a uma longa discussão para a elaboração das questões que compuseram os questionários, que estavam constituídos por dez questões fechadas e de múltipla escolha. Cada uma das escolas selecionadas foi visitada por um subgrupo para a aplicação dos questionários. Na sequência, foi feita a tabulação e a elaboração de gráficos correspondentes a cada uma das respostas dadas. Por último, procedeu-se à análise dos resultados obtidos, que tomou como base os objetivos e quadros de referência discutidos com os professores-formadores envolvidos no projeto. Deste modo, todas as etapas da pesquisa foram partilhadas pelo grupo-classe durante as reuniões semanais para a realização do relatório final.

O referido projeto possibilitou a alunos e docentes uma oportunidade para se trabalhar de forma flexível, reflexiva, colaborativa, dialógica, integrada e interdisciplinar, o que corresponde ao que nos propõe Alonso (2007) ao afirmar que "a flexibilidade, a reflexão sobre a experiência pessoal, a pesquisa e a abertura à inovação, o aprender a aprender, o diálogo e trabalho colaborativo e o respeito pela diferença, revelam-se condições imprescindíveis para navegar ou movimentar-se nesta sociedade" (p. 111). Desta forma, podemos afirmar que as instituições responsáveis pela formação de professores, ao organizarem seus currículos considerando tais princípios, colocam-se em sintonia com as exigências da sociedade atual e do conhecimento construído sobre a formação de professores. 
A seguir, considerando a perspectiva apontada acima, apresentamos a análise das reflexões elaboradas pelos alunos do curso de Licenciatura em Espanhol que participaram da experiência relatada neste artigo.

\subsection{Uma reflexão sobre a experiência}

O nosso contexto de análise é o Relatório elaborado pelo grupo-classe de uma turma do terceiro período da Licenciatura em Espanhol. O relatório tomou como referência os dados recolhidos com a aplicação de questionários direcionados aos professores e estudantes de E/LE que lecionam e estudam nas escolas-campo de investigação.

Sua organização se deu da seguinte forma: na primeira seção, encontramos a análise das questões respondidas pelos professores das escolas públicas pesquisadas. Na segunda, encontramos a análise dos dados coletados com os discentes. A terceira e última parte, segundo uma das alunas integrantes do grupo classe, propõe "(...) que o leitor possa ter um panorama do conhecimento construído por cada um dos grupos e ao mesmo tempo desnudar a confluência de sentimento que envolveu cada um dos sujeitos na elaboração deste trabalho". O Relatório ainda apresenta em anexo as atas lavradas em cada uma das reuniões e os questionários utilizados nas pesquisas.

Uns dos principais objetivos dos $\mathrm{PI}$ dos Cursos de Licenciatura oferecidos pelo IFRN são: integrar as disciplinas e o grupo-classe e contribuir para a formação do professor-pesquisador. Portanto, com o intuito de perceber se tais objetivos tinham sido atingidos, selecionamos duas unidades de contexto: uma que tratava da Análise dos Dados (AD) feita pelos alunos da referida licenciatura e outra que tratava das Considerações Finais (CF) elaboradas por cada um dos grupos participantes. Buscamos identificar nessas unidades, a partir de categorias construídas com base no referencial teórico que alicerça nosso estudo e na leitura do próprio relatório, os indicadores que demonstrassem a importância do PI para a formação do professor-pesquisador e a importância do PI para a integração do grupoclasse, conforme demonstra o quadro a seguir. 


\begin{tabular}{lll}
\multicolumn{2}{l}{ Análise categorial } \\
\hline Categoria & Definição & Indicadores \\
\hline Importância & Importância do PI para a & Importância do PI para formação de \\
do PI & formação do professor- & professor-pesquisador. \\
\cline { 3 - 3 } & pesquisador e para a integração & Importância do PI para integração do \\
& do grupo-classe. & grupo-classe. \\
\hline Integração & Mobilização dos conteúdos das & Disciplinas específicas do ensino da \\
das & disciplinas que integram o plano & Língua Espanhola. \\
\cline { 3 - 3 } disciplinas a & curricular da licenciatura em & Disciplinas de formação social, política \\
partir do PI & Espanhol. & e legal referente ao ensino de Língua \\
& & Espanhola no Brasil. \\
\cline { 3 - 3 } & & Disciplinas didático-pedagógicas. \\
\end{tabular}

Buscamos, ainda, identificar os indicadores que evidenciassem a integração das disciplinas a partir do $\mathrm{Pl}$, com destaque para as disciplinas específicas do ensino da Língua Espanhola; para as disciplinas de formação social, política e legal referente ao ensino dessa língua no Brasil e para as disciplinas didático-pedagógicas.

\subsubsection{Importância do PI para formação do professor-pesquisador}

Com o intuito de selecionarmos as unidades de registro referentes a esse indicador, perguntamo-nos como e por que o PI contribui para a formação do professor-pesquisador.

Podemos observar, na escrita dos licenciandos, vários indícios que nos levam a afirmar que o PI contribui de forma significativa para a formação do professor-pesquisador, como podemos constatar nas citações destacadas abaixo:

"O PI nos deu a oportunidade de construir conhecimento científico buscando diretamente da fonte: a realidade social."

"O PI possibilitou o desenvolvimento de nossa capacidade de comunicação e argumentação."

"Encontramos novos caminhos ou possibilidades diante de questões que muitas vezes parecem imutáveis ou impossíveis de se responder." 
"[O PI] possibilitou vislumbrar além dos limites da sala de aula e expandir os horizontes para o futuro campo de trabalho."

"[O PI] fomenta a pesquisa científica no IFRN. (...) passamos a conhecer um pouco mais do mundo depois dos muros do Instituto."

Em suas análises, os alunos se reportam tanto à construção de um saber no qual a sintonia entre os conceitos científicos e a realidade objetiva da escola pública está sempre presente, quanto ao desenvolvimento da capacidade de comunicação e argumentação, resultando no desenvolvimento do professor-investigador. Este que, segundo Alarcão (2001), é um ser "(...) capaz de se organizar para, perante uma situação problemática, se questionar intencional e sistematicamente com vista à sua compreensão e posterior solução" (p. 6). A condução intencional e reflexiva da pesquisa, os procedimentos metodológicos e a construção de conhecimentos são elementos de partilha permanente na elaboração e discussão do PI.

Segundo nos afirma Demo (1998),

(...) a aproximação, e até certo ponto a coincidência, de educação e pesquisa está sobretudo no ímpeto emancipatório de ambas, já que se alimentam da consciência crítica, questionamento, capacidade de intervenção alternativa, ligação teoria e prática, e assim por diante; assim, educar pela pesquisa significa trabalhar acuradamente a competência emancipatória da pessoa e da sociedade, estabelecendo a relação de sujeitos como dinâmica essencial ( $p$. 86).

Podemos concluir que os atributos destacados na citação acima podem ser mobilizados a partir do trabalho com projetos. A consciência crítica, o questionamento, a capacidade de intervenção são desenvolvidos quando, em contato com os problemas do cotidiano escolar, os alunos, futuros professores, ganham fôlego e emancipação para buscar na teoria possíveis respostas e/ou soluções para os problemas encontrados, contemplando dessa forma a ligação teoria e prática também proposta por Demo (1998). Assim, nossa análise nos leva a concluir que o PI se trata de um instrumento teórico e metodológico importante para a formação do professor-pesquisador.

\subsubsection{Importância do PI para integração do grupo-classe}

Para identificarmos as unidades de registro referentes ao indicador em questão, levantamos dois questionamentos: como e por que o PI é importante na integração do grupo-classe. 
No que diz respeito à integração do grupo-classe, a presença de expressões como sentimento agradável, gratidão, ternas lembranças, esforço válido, nas análises dos futuros professores, permite-nos perceber que o PI pode ser um trabalho gratificante e socializador, tanto para os alunos como para os docentes envolvidos no processo. A este respeito, vale destacar o seguinte trecho retirado do relatório elaborado pelos licenciandos:

"O envolvimento com o grupo-classe e com a (...) orientadora do projeto (...) enriqueceu o currículo semestral (...) uma vez que nessas interações se aprende muito uns aos outros."

"(...) grupos foram formados, e dentro de cada um deles, se deu um vínculo de amizade e companheirismo, na medida em que os resultados propostos eram superados. (...) [tivemos] o amadurecimento no que se refere ao desenvolvimento do trabalho em grupo (...)"

"(..) levaremos ternas lembranças das reuniões semanais do Projeto Integrador, com seus objetivos, prazos e muitas atas, que se somam ao acervo de experiências pertinentes a este trabalho."

"Impressões e sentimentos integram o conteúdo desta atividade científica (...), por isso, se retoma neste momento os 'dados implícitos' (...) para reconhecer o esforço, o empenho e a dedicação da docente responsável pelo projeto e dos discentes envolvidos."

O encontro, o diálogo e a partilha são elementos presentes no PI, além da intersubjetividade, da intercomunicação e da narração, que são elementos fundamentais para a cooperação.

O PI é um trabalho que tem natureza colaborativa. O seu desenvolvimento só se torna possível quando seus participantes adquirem confiança uns nos outros e em si mesmos. Abaixo destacamos duas citações que refletem bem este enunciado.

"(...) percebe-se a contribuição do presente trabalho à formação acadêmica, através das experiências adquiridas ao longo de sua construção e das relações interpessoais vivenciadas por meio dele."

"O caminho percorrido até sua apresentação ao fim do semestre é muito árduo e requer dedicação de todos os envolvidos, mas ao final de tantas horas de trabalho o melhor é perceber que todo o esforço foi válido (...)."

Compreendemos que, ao destacarem as relações interpessoais, o envolvimento e a dedicação de todos os incluídos no processo, os formandos 
apontam para a realização de um trabalho colaborativo em que predominaram a cooperação e a conexão de procedimentos, atitudes e aprendizagens.

Como se pode apreciar, o trabalho analisado neste texto despertou nos alunos a consciência de que eles são sujeitos singulares e capazes de, a partir de um comprometimento ético, construir projetos coletivos.

\subsubsection{Integração das disciplinas a partir do PI}

Observamos que, ao mobilizar os conteúdos das disciplinas cursadas durante os três períodos do curso para análise e interpretação dos dados obtidos com a pesquisa, o grupo-classe (alunos e professores) está trabalhando de forma integrada e interdisciplinar.

\subsubsection{Integração das disciplinas a partir do Pl: Disciplinas} específicas do ensino da Língua Espanhola

Para analisarmos a importância do PI para integração das disciplinas específicas do ensino da Língua Espanhola, selecionamos unidades de registro que demonstrem a mobilização dos conteúdos dessas disciplinas na análise dos dados feita pelos formandos. Tal mobilização foi percebida em falas que se referiram tanto às dificuldades encontradas pelos professores de língua estrangeira, quanto ao desenvolvimento das habilidades linguísticas no processo de ensino e aprendizagem em sala de aula.

Outros conceitos já elaborados pelos alunos são evidenciados quando estes se referem aos valores sociais que cercam o ensino e a aprendizagem do idioma em questão e quando, em suas análises, se referem às convenções culturais que determinam a escolha de uma estrutura gramatical em detrimento de outra. Os alunos ainda se reportam ao sistema fonético e fonológico e aos aspectos semânticos, sintáticos e pragmáticos da língua estudada. Como exemplo, temos as falas abaixo:

"Uma das maiores dificuldades encontradas pelos professores de língua estrangeira é o desenvolvimento das habilidades linguísticas no processo de ensino e aprendizagem em sala de aula."

"(...) entende-se que ter acesso aos diversos tipos de dicionários deve ser mais uma das reivindicações do docente da língua espanhola." 
"(...) o professor deve saber utilizar o dicionário para ensinar aos alunos; então, fica evidente que para utilizar esse recurso a formação é algo imprescindível (...) ter qualidade no ensino (...)."

"Um diálogo pode ser trabalhado somente do ponto de vista estrutural, mas também pode ser analisado em sala de aula percebendo os valores sociais que cercam aquela conversa, as convenções culturais que determinam a escolha de uma estrutura gramatical em detrimento de outra."

"(...) é muito importante frisar que a função da docência da língua espanhola como meio de ampliação cultural não quer dizer (...) só depositar conteúdos culturais em formas linguísticas, mas também de interpretar o que se quis transmitir junto ao código linguístico."

Na última citação destacada acima, os alunos alertam para a função social do professor de E/LE. Consideramos ainda que a própria elaboração dos questionários denota a integração dessas disciplinas. Questões sobre o uso do dicionário, sua importância para o estudo do E/LE, cuidados e recomendações evidenciam o acervo conceitual construído durante os três semestres de curso.

Tudo isto permite-nos afirmar que o $\mathrm{PI}$ contribui para o desenvolvimento de uma aprendizagem significativa. Segundo nos alertam Valadares e Moreira (2009), "(...) um factor importante para que ocorra a aprendizagem significativa é a motivação, o interesse, no fundo a predisposição do aprendente para aprender significativamente" (p. 72). A motivação e o interesse são mobilizados pela participação ativa dos alunos na elaboração e consecução dos projetos. Ao identificarem os problemas vivenciados nas escolas - campo de investigação -, os alunos recorrem às teorias estudadas para virem a entendê-los e, quando possível, virem a apontar soluções, aguçando, dessa forma, a predisposição para aprender significativamente.

Podemos perceber, ao longo da análise do relatório - objeto de estudo deste trabalho -, que os alunos da Licenciatura em Espanhol mobilizaram os conteúdos das disciplinas específicas ao analisarem os dados recolhidos. 
4.2.3.2. Integração das disciplinas a partir do Pl: Disciplinas de formação social, política e legal referente ao ensino de Língua Espanhola no Brasil

O PI evidencia a importância da formação integral e articulada do professor de Língua Espanhola. Com o referido trabalho, os alunos mobilizaram diversos saberes para o estudo e para o entendimento das questões levantadas. A integração dos saberes específicos referentes ao ensino do E/LE com os saberes de formação social, política, e legal demonstra que é possível um currículo integrado na formação do professor. Uma formação que busca integrar os conteúdos específicos de Língua Espanhola com os conteúdos da formação geral do professor torna-se importante para o futuro docente, pois, segundo Kincheloe (2006),

(...) à medida que aprendem acerca dos contextos históricos, sociais, culturais, políticos, económicos (...), desenvolvem a importante capacidade de compreender a génese da política e do propósito educativo, para que possam participar de forma mais plena na conversação pública em torno da educação (p. 75).

Para ilustrar a mobilização dos conteúdos dessas disciplinas, destacamos os seguintes trechos:

"O ensino de E/LE (...) enfrenta questões peculiares; (...) antes da análise desta problemática é importante a compreensão dos parâmetros legais que contextualizam o ensino de línguas na educação brasileira."

"Com o advento da Lei 11.161/05, que tornou obrigatória a oferta do Espanhol nas escolas públicas do Ensino Médio, os alunos se encontram com mais um idioma estrangeiro e mais aporte cultural, vê-se que esta é a segunda maior motivação, o que de certa forma está interligada com a preocupação de um lugar no mercado de trabalho (...)."

"A Lei de Diretrizes e Bases - no 9394/96 (LDB), disposição normativa que rege toda a organização da educação no país, trata da obrigatoriedade da inclusão, a partir do nível fundamental, de pelo menos uma disciplina de língua estrangeira."

"Mediante a questão social, cultural e econômica, outro fator não poderia ser esquecido: o aspecto legal."

"Com o desenvolvimento do conhecimento e das tecnologias, a humanidade percorre um processo de reconstrução dos seus papéis e funções cotidianas; desta forma, todos os setores que constituem a sociedade estão envolvidos nessa nova ordem que o mundo assume." 
As falas dos futuros professores que se reportam às "Leis de Diretrizes e Bases" da Educação Brasileira referem-se às disposições normativas que regem a organização da educação no país, analisam os fatores que determinaram a obrigatoriedade da oferta do Espanhol nas escolas públicas do Ensino Médio, além de refletirem sobre o papel da escola na sociedade contemporânea. Observamos, pois, que, para "conhecer a realidade dos processos de ensino e aprendizagem do Espanhol nas escolas públicas de Ensino Médio de Natal", os alunos da turma de Licenciatura em Espanhol de 2010-2 recorreram às diversas disciplinas de forma integrada e interdisciplinar.

4.2.3.3. Integração das disciplinas a partir do Pl: Disciplinas didáticopedagógicas

Compreendemos que a especificidade da instituição escolar se encontra na ação intencional desenvolvida por professores e alunos para ensinar e aprender. Com os projetos integradores, os alunos adquirem um arcabouço teórico e metodológico que contribui não só para a intencionalidade da prática docente, como também para o seu desenvolvimento crítico e reflexivo. Com isto, compreendem que a escola ganha relevância quando a vida e o mundo do trabalho se fazem presentes na relação estabelecida entre ensino e aprendizagem. Tal observação tornase importante porque, segundo Alonso (2006), "a falta de relevância das aprendizagens escolares para a vida e para o mundo do trabalho e uma competição cada vez maior entre o conhecimento adquirido dentro da escola e o adquirido fora desta, são alguns dos problemas fulcrais da escolarização actual (...)" (p. 5).

Nessa mesma perspectiva, os alunos, ao analisarem os questionários por eles aplicados, destacam que:

"(...) é importante o empenho do professor para trazer temas que despertem o interesse dos alunos e a participação ativa dos estudantes durante a aula (...)".

"(...) é essencial que os sujeitos [alunos e professores] envolvidos no processo trabalhem em conjunto para o alcance dos objetivos planejados e não apenas executem de forma mecânica as ações programadas." 
"(...) por meio de discussões, debates, em sala de aula, o professor de espanhol pode trabalhar a habilidade de produção oral e logo seguir para atividades de elaboração de textos escritos, porque isso não demanda grandes dispêndios de tempo nem exige instrumentos tecnológicos avançados."

"Os recursos didáticos são grandes auxiliares do processo de ensino aprendizagem de qualquer disciplina, em especial daquelas de língua estrangeira, uma vez que podem estimular o aluno a participar ativamente das aulas, deixando as classes mais interessantes."

"(...) cabe ao docente fazer escolhas, quando possível, daqueles recursos que melhor atendam suas necessidades. No entanto, para isso é preciso que esses professores tenham claros os objetivos que desejam alcançar com suas aulas como também tenham formação para utilizá-los de maneira satisfatória, para que seu uso não seja influência de modismos, ou meramente mecânico."

Os alunos, futuros professores, destacam a importância de temas que despertem o interesse do grupo-classe, evidenciam a construção coletiva do conhecimento escolar por meio da definição de objetivos que sejam comuns a todos os integrantes desse processo e apontam a sistematização didática como especificidade do fazer docente. Ressaltam, ainda, a importância de uma formação de professores que possibilite uma ação didática consciente, particularmente, no que diz respeito às escolhas didático-pedagógicas. Tudo isso nos leva a afirmar que as disciplinas dessa área do conhecimento foram mobilizadas na análise dos dados recolhidos pelo PI apresentado neste artigo.

\section{Considerações finais}

Com o objetivo de problematizar o papel da investigação nos cursos de formação inicial de professores, escrevemos este artigo. Buscámos, inicialmente, responder à seguinte questão: Em que medida experiências interdisciplinares baseadas na construção de PI podem contribuir para a integração curricular e para o desenvolvimento de atitudes de pesquisa e de colaboração?

Nossa análise nos permite afirmar que a integração e o desenvolvimento de atitudes de pesquisa e colaboração são resultantes, basicamente, de um currículo de formação e de condições organizacionais que possibilitem a relação teoria e prática, o diálogo entre as disciplinas, a 
reflexão e a crítica. Para tanto, as instituições formadoras devem organizar-se de modo a permitir o trabalho integrado e interdisciplinar. Um segundo ponto considerado foi a disponibilidade dos professores de diferentes áreas disciplinares partilharem suas experiências, seus saberes, suas certezas e incertezas.

Consideramos, ainda, que o trabalho colaborativo, na profissão docente, depende em grande medida das experiências vivenciadas nos cursos de formação inicial de professores, os quais necessitam de uma organização didático-pedagógica que possibilite ao futuro docente participar de práticas interdisciplinares, a exemplo do trabalho com projetos. É neste sentido que apontamos os PI como um procedimento teórico e metodológico que viabiliza a interdisciplinaridade e cultiva nos formandos o gosto pela investigação.

O PI por nós analisado realçou a compreensão dos contextos escolares através do contato direto com a realidade do cotidiano escolar. Neste sentido, os conteúdos das disciplinas contributivas foram mobilizados a partir da participação dos professores e do interesse dos alunos - futuros docentes - por entender a realidade estudada. Situações que permitiram aos alunos agir e refletir sobre as ações e sobre os resultados que fizeram sentido e que foram construídos a partir da produção de elementos cognitivos saídos de diferentes matérias que detêm um potencial de associação e de complementaridade (Lenoir, 1998) caracterizaram o trabalho analisado.

A nossa análise nos permite afirmar que, ao trabalharem com projetos, professores e alunos abrem a possibilidade de incorporar ao currículo conteúdos construídos no "chão" da escola. Os projetos implicam, tanto para os professores formadores quanto para os alunos formandos, o desenvolvimento das capacidades reflexiva, investigativa, criativa e colaborativa, pois constituem-se a partir de uma perspectiva do currículo como práxis emancipadora.

Após as reflexões aqui proporcionadas, percebemos a importância de um estudo mais aprofundado que investigue como se dá a organização do trabalho dos professores formadores, com vistas ao desenvolvimento do currículo integrado. 


\section{Notas}

1 A este respeito, pode-se consultar o Relatório do NUPED intitulado "Investigando a implementação do ensino médio integrado aos cursos técnicos de nível médio no CEFET-RN a partir de 2005: O currículo e a gestão", disponível em: http://portal.ifrn.edu.br/pesquisa/nucleos/nucleo-de-pesquisa-em-educacao/ Relatorio\%20Final_NUPED.pdf/view.

2 A Lei Federal Brasileira de $n^{\circ} 11.741$, de 16 de julho de 2008, no seu Artigo 39, determina que: "A educação profissional e tecnológica, no cumprimento dos objetivos da educação nacional, integra-se aos diferentes níveis e modalidades de educação e às dimensões do trabalho, da ciência e da tecnologia".

3 Desde 2005, trabalhamos como Coordenadora de projetos integradores no Curso de Licenciatura em Espanhol. Para este trabalho escolhemos o PI desenvolvido no semestre letivo de 2010-2, porque este possui um vasto registo organizado e sistematizado, o que nos permite utilizar a análise de conteúdo como estratégia metodológica para a elaboração deste artigo.

4 A interdisciplinaridade, neste estudo, é entendida como um saber que frisa a interdependência, a interação e comunicação existentes entre as disciplinas, facilitando a integração do conhecimento em um todo significativo.

5 Vale ressaltar que, nos Cursos de Licenciatura oferecidos pelo IFRN, as disciplinas específicas são oferecidas concomitantemente com as disciplinas pedagógicas.

\section{Referências}

Alarcão, I. (2001). Professor investigador. Que sentido? Que formação? In B. P. Campos (Org), Formação profissional de professores no ensino superior. Porto: INAFOP/Porto Editora.

Alonso, L. (2000). A construção social do currículo: Uma abordagem ecológica e práxica. Revista de Educação, IX(1), 53-67.

Alonso, L. (2007). Desenvolvimento profissional dos professores e mudança educativa: Uma perspectiva de formação ao longo da vida. In M. Flores \& I. C. Viana (Orgs.), Profissionalismo docente em transição: As identidades dos professores em tempos de mudança (pp. 109-129). Braga: Universidade do Minho.

Alonso, L., \& Silva, C. (2005). Questões críticas acerca de um currículo formativo e integrado. In L. Alonso \& M. C. Roldão, Ser professor de primeiro ciclo: Construindo a profissão (pp. 41-63). Coimbra: Editora Almedina.

Canário, R. (2002). Formação inicial de professores: Que futuro(s)? Síntese dos relatórios de avaliação dos cursos para o $3^{\circ}$ ciclo de ensino básico e ensino secundário. In N. Afonso \& R. Canário, Estudos sobre a situação da formação inicial de professores. Caderno da formação de professores, no 4. Porto: Porto Editora.

Day, C. (2001). Desenvolvimento profissional de professores: Os desafios da aprendizagem permanente. Porto: Porto Editora. 
Demo, P. (1998). Educar pela pesquisa. Campinas, SP: Autores Associados.

Fazenda, I. C. A. (1995). Interdisciplinaridade: História, teoria e pesquisa (2 ${ }^{\mathrm{a}}$ ed.). Campinas, SP: Papirus.

Freire, P. (1996). Pedagogia da autonomia: Saberes necessários à prática educativa. São Paulo: Paz e Terra.

Freire, P. (2004). Educación y participación comunitaria. In M. Castells, R. Flecha, P. Freire, H. Giroux, D. Macedo, \& P. Willis, Nuevas perspectivas críticas en educación - Congreso Internacional Nuevas Perspectivas Críticas en Educación. Barcelona: Paidós Educador.

Gadotti, M. (2003). Concepção dialética da educação: Um estudo introdutório. São Paulo: Cortez.

Hernàndez, F. (1998). Transgressão e mudança na educação: Os projetos de trabalho. Porto Alegre: ArtMed.

Instituto Federal de Educação, Ciência e Tecnologia do Rio Grande do Norte [IFRN] (2010). Projeto político-pedagógico do IFRN: Uma construção coletiva - Texto inicial/Capítulo 02. Disponível em http://www2.ifrn.edu.br/ppi/lib/exe/fetch.php? media=cap02:cap02_secao01_reescrita_secoes02a04_inicial.pdf

Instituto Federal de Educação, Ciência e Tecnologia do Rio Grande do Norte [IFRN] (s/d). Projeto político-pedagógico do IFRN: Uma construção coletiva. Disponível em http://www2.ifrn.edu.br/ppi/doku.php (acesso em 21 de janeiro de 2012).

Japiassú, H. (1996). Dicionário básico de filosofia. Rio de Janeiro: Jorge Zahar Ed.

Kincheloe, J. (2006). Construtivismo crítico. Mangualde: Edições Pedago.

Lenoir, Y. (1998) Didática e interdisciplinaridade: Uma complementaridade necessária e incontornável. In I. Fazenda (Org.), Didática e interdisciplinaridade (pp. 45-75). Campinas, SP: Papirus.

López, P., Gallego-Largo, J. R., Blanco, C. S., \& Sanz, A. S. (1992). Diseño del currículo en el aula: Una propuesta de autoformación. Madrid: Mare Nostrum Ediciones Didáticas, $\mathrm{SA}$.

Ramos, M. N. (2012). Currículo integrado. Disponível em http://www.epsjv.fiocruz.br/ dicionario/verbetes/curint.html\#topo (acesso em 21 de janeiro de 2012).

Roegiers, X., \& De Ketele, J. M. (2004). Uma pedagogia da integração: Competência e aquisição no ensino. Porto Alegre: ArtMed.

Roldão, M. C. (2005). Formação de professores: Construção do saber profissional e cultura da profissionalização - Que triangulação? In L. Alonso \& M. C. Roldão, Ser professor de primeiro ciclo: Construindo a profissão. Coimbra: Editora Almedina.

Severino, A. J. (2004). A concepção filosófica do educar e a construção da filosofia da educação. In D. Rocha (Org.), Filosofia da educação: Diferentes abordagens. Campinas, SP: Papirus.

Silva, C. M. R. (2011). Tornar-se professor: Desenvolvimento curricular e construção do conhecimento profissional (Tese de doutoramento). Universidade do Minho, Braga.

Valadares, A. V., \& Moreira, M. A. (2009). A teoria da aprendizagem significativa: Sua fundamentação e implicação. Coimbra: Editora Almedina. 
WORK PROJECTS: A TEACHER INTEGRATIVE EXPERIMENT IN TEACHERS' PREPARATION

\section{Abstract}

This article aims to discuss the role of research in the initial teacher education courses based on an experience with integration projects (IP). Its development is based on three organizing concepts: initial teacher training, integrated curriculum and interdisciplinarity. It also discusses the importance of a teacher education curriculum which enables the relation between theory and practice, as well as the dialogue between subjects, reflection and critique. This work also highlights the importance of the availability of teachers from different disciplines for sharing their experiences, their knowledge, their certainties and uncertainties. It has as an analysis context a report prepared by a third period class (second year college) with major in Spanish. It is based on the principles of qualitative research. This work emphasizes the indicators which point to the integration of disciplines starting from the IP and its importance to the formation of the research teacher and for the integration of the group-class.

Keywords

Initial teacher training; Integrated curriculum; Integrative projects

LES PROJETS DE TRAVAIL: UNE EXPÉRIENCE INTÉGRATRICE DANS LA FORMATION INITIALE DE PROFESSEURS

\section{Résumé}

Ce travail qualitatif a comme objectif problématiser le rôle de la recherche dans les cursus de formation initiale de professeurs à partir du récit d'une expérience avec des projets intégrateurs (PI). Son développement a comme base trois concepts organisateurs: formation initiale de professeurs, curriculum intégré et interdisciplinarité. II discute l'importance d'un curriculum de formation qui permette la relation entre théorie et pratique, le dialogue entre 
les disciplines, la réflexion et la critique. II met en évidence l'importance de la disponibilité des professeurs de différents domaines disciplinaires dans l'échange de leurs expériences, leurs savoirs, leurs certitudes et incertitudes. Il a comme contexte d'analyse le rapport élaboré par le groupe-classe d'un groupe du troisième trimestre de la licence en Espagnol. II met en évidence les indicateurs qui montrent l'intégration des disciplines à partir du PI et l'importance de celui-ci pour la formation du professeur-chercheur et pour l'intégration du groupe-classe.

Mots-clé

Formation initiale de professeurs; Curriculum intégré; Projets intégrateurs

Recebido em fevereiro/2014

Aceite para publicação em outubro/2014

i Diretoria Acadêmica de Ciências do IFRN Campus Natal-Central, Instituto Federal do Rio Grande do Norte, Brasil.

Toda a correspondência relativa a este artigo deve ser enviada para: Eulália Neto, Rua Des. José Gomes da Costa, 1890, apto 1402, Capim Macio, Natal-RN, Brasil, CEP 59.082-140. E-mail: eulalia.gusmao@ifrn.edu.br 